\title{
Article \\ One- and Two-Step Kinetic Data Analysis Applied for Single and Co-Culture Growth of Staphylococcus aureus, Escherichia coli, and Lactic Acid Bacteria in Milk
}

\author{
Pavel Ačai ${ }^{1}$, L'ubomír Valík ${ }^{2, * \mathbb{D}}$ and Alžbeta Medved'ová ${ }^{2}$ (D) \\ 1 Institute of Chemical and Environmental Engineering, Faculty of Chemical and Food Technology, \\ Slovak University of Technology in Bratislava, SK-812 37 Bratislava, Slovakia; pavel.acai@stuba.sk \\ 2 Department of Nutrition and Food Quality Assessment, Institute of Food Science and Nutrition, \\ Faculty of Chemical and Food Technology, Slovak University of Technology in Bratislava, Radlinského 9, \\ SK-812 37 Bratislava, Slovakia; alzbeta.medvedova@stuba.sk \\ * Correspondence: lubomir.valik@stuba.sk; Tel.: +421-2-59325-518
}

check for

updates

Citation: Ačai, P.; Valík, L'.;

Medved'ová, A. One- and Two-Step

Kinetic Data Analysis Applied for

Single and Co-Culture Growth of

Staphylococcus aureus, Escherichia coli, and Lactic Acid Bacteria in Milk.

Appl. Sci. 2021, 11, 8673. https://

doi.org/10.3390/app11188673

Academic Editors: David Ian Ellis and Lubomir Valik

Received: 23 August 2021

Accepted: 14 September 2021

Published: 17 September 2021

Publisher's Note: MDPI stays neutral with regard to jurisdictional claims in published maps and institutional affiliations.

Copyright: (c) 2021 by the authors. Licensee MDPI, Basel, Switzerland. This article is an open access article distributed under the terms and conditions of the Creative Commons Attribution (CC BY) license (https:// creativecommons.org/licenses/by/ $4.0 /)$.

\begin{abstract}
The objective of this study was to compare one- and two-step kinetic data analysis approaches to describe the growth of Staphylococcus aureus, Escherichia coli, and lactic acid bacteria Fresco 1010 starter culture in milk under isothermal conditions between 10 and $37^{\circ} \mathrm{C}$. The primary Huang model (HM) and secondary square root model were applied to lag times and growth rates of each of the population. The one-step approach for single cultures data enabled the direct construction of a tertiary model combining primary and secondary models to determine parameters from all growth data, thus minimizing the transfer of errors from one model to another. The statistical indices showed a significant improvement in the prediction capability provided by this approach. Then, a one-step approach combining the primary Huang, Giménez, and Dalgaard model (H-GD) with the secondary square root model was used to simultaneously model the growth of the populations mentioned above in co-culture under the same conditions. Independent isothermal data sets were chosen for validation of the growth description of single cultures (HM) and co-culture (H-GD) using validation factors, including the bias $\left(B_{f}\right)$ and accuracy $\left(A_{f}\right)$. For example, the values of $A_{f}$ for the one-step approach range from 1.17 to 1.20 and 1.04 to 1.08 for single cultures and co-culture, respectively, demonstrating high accuracy. Thus, this approach may be used for co-culture growth description in general or specifically, e.g., in various types of lactic acid fermentation, including artisanal cheese-making technology.
\end{abstract}

Keywords: S. aureus; E. coli; lactic acid bacteria; one-step modelling in co-culture

\section{Introduction}

The microbial growth and metabolic activity of participating microbial populations depend on the actual environmental conditions represented by a group of intrinsic and extrinsic factors, as well as implicit factors that cover the interaction between the present microbiota. These are generally considered the key factors contributing to the quality and safety of raw food materials and final food products. In the case of raw milk cheeses, such as traditional dairy products in some European regions, including Slovakian ones, the presence and activity of undesirable microbial populations in raw milk are the factors limiting cheese safety. Their interactions with lactic acid bacteria (LAB) are the core of scientists' interest in preventing undesirable growth during the fermentation of milk and cheese ripening.

A commercially available LAB culture, Fresco DVS 1010, significantly inhibits S. aureus and E. coli growth during their cocultivation in milk [1-3], lumpy cheeses [4], and in pasta filata types of cheese production [5,6]. In addition, the effect of temperature and $\mathrm{NaCl}$ addition on the growth of Fresco culture in milk was described by Medved'ová et al. [7]. 
The concern about the presence of S. aureus and E. coli in foods is related to their frequent occurrence in raw milk and raw milk dairy products. The prevalence of E. coli and S. aureus in Slovak raw milk cheeses is in the range of $45-87 \%$ and $10-13 \%$, respectively [8]. Both bacterial species are considered important process hygiene indicators as well as indicators of cheese quality defects; they are also pathogenic organisms with the ability to endanger the health of consumers. S. aureus has a remarkably wide range of pathogenic factors causing different infectious diseases; it can produce 26 different staphylococcal enterotoxins and enterotoxin-like molecules causing food-borne outbreaks. E. coli may be present in raw milk and other products not only as a saprophytic organism: its pathogenic strains may occur with low prevalence. Thus, in addition to food-borne diseases, enteric, enterohemorrhagic, diarrheal, and other diseases may result from primary or secondary E. coli contamination in food [9].

The application of mathematical models in predictive microbiology is useful for describing and predicting microbial growth, interactions between microbes, and their responses to environmental conditions. Traditionally, a two-step procedure is used for modeling microbial growth, inactivation, or survival. According to Whiting and Buchanan [10], after collecting a sufficient number of usually isothermal curves representing kinetic changes over time under different environmental conditions, the pertinent kinetic parameters are calculated using a suitable primary model. Next, considering the effect of environmental conditions, the kinetic parameters are modeled. Finally, the secondary modeling outputs are incorporated back into the primary models to predict of microbial behavior over time. Most of the current freely available prediction tools, also considered tertiary models, were constructed using this approach [11]. However, according to Huang [12], one major drawback of this standard two-step approach is the accumulation and propagation of errors in each step of data analysis, which may affect the accuracy of prediction.

The traditionally used two-step modelling approach may be significantly improved by applying one-step data analysis to directly construct the models integrating primary and secondary models. This minimizes the global error. It is also believed that one-step data analysis method is superior, providing better fits to the data and producing directly interpretable regression diagnostics and standard errors [11,13]. Although advanced knowledge and skills in statistics and computer programming are required to perform data analysis [12], an increasing number of one-step approaches applied in several growth and inactivation studies [14-18] have recently been published.

The objective of this study was to apply one- and two-step kinetic data analysis approaches to describe single-culture growth and, subsequently, to describe the co-culture growth of S. aureus, E. coli, and LAB in milk under isothermal conditions between 10 and $37^{\circ} \mathrm{C}$. The outputs of the evaluated approaches could be used for growth prediction or for exposure assessments of microbial populations involved in food fermentation.

\section{Materials and Methods}

\subsection{Growth Studies, Data Collection, and Enumeration of Microorganisms}

The growth data of S. aureus, E. coli, and LAB in Fresco culture, all in single and co-culture, were collected from the previously published growth curves $[2,3,19]$ at different isothermal temperatures $\left(10,12,15,18,21,25,30,35\right.$, and $\left.37^{\circ} \mathrm{C}\right)$. Briefly, the $S$. aureus 2064 and E. coli BR strains were isolated from Slovak ewe's cheese and traditional Bryndza cheese, respectively. The isolates were maintained in BHI broth (Sigma Aldrich, St. Louis, $\mathrm{MO}, \mathrm{USA})$ at $5 \pm 1{ }^{\circ} \mathrm{C}$ prior to growth analysis. The mesophilic commercial LAB culture Fresco DVS 1010 (Christian Hansen, Hørsholm, Denmark), consisting of Lactococcus lactis subsp. lactis, L. lactis subsp. cremoris, and Streptococcus salivarius subsp. thermophilus, was used as the third population. The culture was kept frozen at $-45^{\circ} \mathrm{C}$. S. aureus was enumerated on Baird-Parker agar (Merck, Darmstadt, Germany) according to EN ISO 6888-1 [20] with aerobic incubation at $37 \pm 0.5^{\circ} \mathrm{C}$ for $48 \mathrm{~h}$; E. coli was enumerated on Chromocult agar (Merck, Darmstadt, Germany) after $24 \mathrm{~h}$ incubation at $37 \pm 0.5^{\circ} \mathrm{C}$ according to National 
Standard Method F23 [21]. The LAB were enumerated on M17 agar (Merck, Darmstadt, Germany) after $48 \mathrm{~h}$ incubation at $30 \pm 0.5^{\circ} \mathrm{C}$ according to EN ISO 15214 [22].

\subsection{Mathematical Models}

The primary Huang model [23] and secondary square root model applied to growth rate and lag time were used for comparison of one- and two-step data analysis methods for the single growth of S. aureus, E. coli, and LAB Fresco culture in milk under suboptimal temperature conditions $\left(10-37^{\circ} \mathrm{C}\right)$. The goodness-of-fit of the tertiary HMs was evaluated with the global sum of square error (SSE), the adjusted determination coefficient $\left(R_{a d j}{ }^{2}\right)$, and the root mean square error (RMSE), and significant statistical differences between the two- and one-step approaches for the growth prediction of each microorganism were determined by post hoc analyses using Tukey's test [23].

The one-step approach combining the primary Huang, Giménez, and Dalgaard model (H-GD) $[24,25]$ with the secondary square root model was used for the prediction of the simultaneous growth of competitive bacterial populations in milk. Its prediction ability and accuracy were tested with the independent isothermal data sets using validation indices.

\subsubsection{Primary and Secondary Models}

For the prediction of the microbial growth of S. aureus, E. coli, and LAB as single cultures in milk, the primary HM [24] was used (Equation (1)):

$$
\begin{gathered}
\frac{d x}{d t}=\frac{\frac{\mu_{\max }}{\ln 10}}{1+10^{-\alpha\left(t-t_{\lambda}\right)}}\left(1-10^{\left(x-x_{\max }\right)}\right) \\
t=0 \quad x=x_{0}
\end{gathered}
$$

where $\mu_{\max }$ is the maximum specific growth rate $\left(\mathrm{h}^{-1}\right), t_{\lambda}$ is the lag time $(\mathrm{h}), \alpha$ is the lag phase transition coefficient that takes a value of 4 [24], and concentrations of microorganisms are expressed in $\log \mathrm{CFU} \mathrm{mL}{ }^{-1}$, which include $x=\log N, x_{0}=\log N_{0}$, and $x_{\max }=\log N_{\max }$ representing the real $(N)$, initial $\left(N_{0}\right)$, and maximum numbers $\left(N_{\max }\right)$. The optimized parameters of the HM in its modified form are $\mu_{\max }, t_{\lambda}, x_{0}$, and $x_{\max }$. Both $\mu_{\max }$ and $t_{\lambda}$ are a function of temperature. The Ratkowsky square root model [26] was used to determine the relationship between the maximum specific growth rate and temperature under suboptimal conditions according to the equation:

$$
\sqrt{\mu_{\max }}=b_{T} \cdot\left(T-T_{\min }\right)
$$

where the regression coefficient $b_{T}\left(\mathrm{~h}^{-1}{ }^{\circ} \mathrm{C}^{-1}\right)$ is the slope and depends on additional growth conditions and the microorganism involved, $T\left({ }^{\circ} \mathrm{C}\right)$ is the temperature, and $T_{\min }$ is the theoretical minimum temperature for growth. The square root relation between the lag time $\left(t_{\lambda}\right)$ parameter and temperature by Whithing and Buchanan [10] was used in the HM as follows:

$$
\sqrt{\frac{1}{t_{\lambda}}}=b_{\lambda} \cdot\left(T-T_{\min }\right)
$$

where $b_{\lambda}$ is the regression coefficient.

\subsubsection{Modeling Single Cultures}

Both one-step and two-step kinetic data analysis methods were applied for the growth prediction of single cultures of S. aureus, E. coli, and Fresco culture in milk. Using the twostep approach, each growth curve was analyzed using the HM (Equation (1)) to determine its parameters. Subsequently, suitable secondary models, Equations (2) and (3), were used to analyze the effect of temperature on the maximum growth rates and lag times calculated from the primary model. Once the primary and secondary models were used, all they were integrated in the prediction tertiary model, in our case, the two-step $\mathrm{HM}_{2-\mathrm{s}}$. As the initial 
values $x_{0}$ were slightly different in the specific temperature experiments, the parameter vector $X_{0}$ used for forward prediction contained nine parameters $\left(x_{0,10}, x_{0,12}, x_{0,15}, x_{0,18}\right.$, $x_{0,21}, x_{0,25}, x_{0,30}, x_{0,35}$, and $x_{0,37}$ ). The maximum population density $x_{\max }$ for each single microorganism was found to be independent of temperature; therefore, the average of the values estimated at isothermal conditions was used. The growth parameters $\mu_{\max }$ and $t_{\lambda}$ were replaced with square root secondary models (Equations (2) and (3)), respectively). Subsequently, the tertiary $\mathrm{HM}_{2-\mathrm{S}}$ for growth predictions of single cultures of $S$. aureus, E. coli, and Fresco culture was found to have 13 parameters (Equation (4)).

Applying the one-step integrated method reported by Huang [12,27], all isothermal growth curves of the given single bacterial populations were simultaneously analyzed using the HM (Equation (1)) and the secondary square root models (Equations (2) and (3)) in one step, to directly construct the tertiary $\mathrm{HM}_{1-\mathrm{S}}$ and minimize the global sum of square error (SSE). By analogy, the $\mathrm{HM}_{1-S}$ contains the same 13 parameters (Equation (4)) as the tertiary $\mathrm{HM}_{2-S} ; 9$ different initial values $x_{0}$ for each incubation temperature, the estimated average value of $x_{\max }$, and parameters $b_{T}, T_{\min }$, and $b_{\lambda}$ from both square root models (Equations (2) and (3)).

$$
p_{H M}=\left\{X_{0} ; x_{\max } ; b_{T} ; T_{\min } ; b_{\lambda}\right\}
$$

where $p_{\mathrm{HM}}$ is the vector of the parameters for the growth prediction of S. aureus, E. coli, and Fresco culture.

The goodness-of-fit of the tertiary $\mathrm{HM}_{1-\mathrm{S}}$ and $\mathrm{HM}_{2-\mathrm{S}}$ was evaluated with the global sum of square error (SSE), the adjusted determination coefficient $\left(R_{a d j}{ }^{2}\right)$, and the root mean square error (RMSE) to test the suitability of the models to fit the whole set of observation points according to Equations (5)-(7), respectively:

$$
\begin{gathered}
S S E=\sum_{i=1}^{n}\left(x_{i}^{\exp }-x_{i}^{\mathrm{cal}}\right)^{2} \\
R_{a d j}^{2}=1-\frac{\frac{S S E}{d f_{E}}}{\frac{S S T}{d f_{T}}} \\
R M S E=\sqrt{\frac{\sum_{i=1}^{n}\left(x_{i}^{\exp }-x_{i}^{\mathrm{cal}}\right)^{2}}{n-p}}
\end{gathered}
$$

where $x_{\mathrm{i}}{ }^{\text {exp }}$ and $x_{\mathrm{i}}^{\text {cal }}$ correspond to the observed and predicted $\log \mathrm{CFU} \mathrm{mL} \mathrm{L}^{-1}$ values, respectively, $n$ is the total number of data points, $p$ is the number of parameters, SST is the total sum of square errors, $d f_{\mathrm{E}}=n-p$ and $d f_{\mathrm{T}}=n-1$ are the degrees of freedom.

Statistically significant differences between the one- and two-step approaches for growth prediction of each microbial population were evaluated by post hoc analyses using Tukey's test [23] after obtaining a significant F ratio from the analysis of variance. Tukey's procedure uses a single critical range of the mean, expressed as follows:

$$
C R_{T}=q\left(\alpha, k, d f_{w}\right) \sqrt{\frac{M S S_{w}}{n}}
$$

where $C R_{T}$ is the critical range for Tukey's test; $q\left(\alpha, k, d f_{w}\right)$ is the studentized range of Student's $t$-statistic for the maximum number of treatment groups being compared, in which $k$, the compared groups, is the SSE data sets for two and one-step approaches; $d f_{w}$ is the degree of freedom within the groups; $\alpha$ is the level of significance; $M S S_{w}$ is the mean square value from the analysis of variance table; and $n$ is the number of points in each data set. Any difference between $S S E$ means $\left(\triangle S S E_{m}\right)$ equal to or greater than $C R_{T}$ would be significantly different at the $\alpha$ level of significance. 
The prediction capability of the tertiary model was tested through the validation bias $\left(B_{f}\right)$ and accuracy $\left(A_{f}\right)$ factors [28], calculated according to Equations (9) and (10), respectively.

$$
\begin{gathered}
B_{f}=10^{\sum_{i=1}^{n}\left(\log x_{i}^{\text {cal }}-\log x_{i}^{\text {exp }}\right)}{ }^{n} \\
A_{f}=10 \sqrt{\frac{\sum_{i=1}^{n}\left(\log x_{i}^{\text {cal }}-\log x_{i}^{\text {exp }}\right)^{2}}{n}}
\end{gathered}
$$

Independent data sets of different S. aureus isolates B1 and D1 [29] and E. coli LC [30] were constructed in our laboratory at different time periods, obtained similarly in milk in the temperature range of $15-35^{\circ} \mathrm{C}$ (S. aureus) and $10-37^{\circ} \mathrm{C}($ E. coli $)$.

\subsubsection{Modeling the Microbial Interaction in Co-Cultures}

To directly construct the tertiary model of the simultaneous growth of S. aureus, E. coli, and LAB in milk, the H-GD model [25], with the competition coefficients and secondary models (Equations (2) and (3)), was used to describe interspecies competition growth for all isothermal growth curves. The suggested model, as a system of the ordinary differential equations with the initial conditions, can be written as follows:

$$
\begin{gathered}
\frac{d x_{E c}}{d t}=\frac{\frac{\mu_{\max }^{E c}}{\ln 10}}{1+10^{-\alpha\left(t-t_{\lambda}^{E c}\right)}}\left[\left(1-10^{\left(x_{E c}-x_{\max , E c}\right)}\right)\left(1-10^{\left(x_{S a}-x_{\max , S a}\right)}\right)\left(1-10^{\left(x_{L A B}-x_{\max , L A B}\right)}\right)\right] I_{E S L} \\
\frac{d x_{S a}}{d t}=\frac{\frac{\mu_{\max }^{S a}}{\ln 10}}{1+10^{-\alpha\left(t-t_{\lambda}^{S a}\right)}}\left[\left(1-10^{\left(x_{S a}-x_{\max , S a}\right)}\right)\left(1-10^{\left(x_{E c}-x_{\max , E c}\right)}\right)\left(1-10^{\left(x_{L A B}-x_{\max , L A B}\right)}\right)\right] I_{S E L} \\
\frac{d x_{L A B}}{d t}=\frac{\frac{\mu_{\max }^{L A B}}{\ln 10}}{1+10^{-\alpha\left(t-t_{\lambda}^{L A B}\right)}}\left[\left(1-10^{\left(x_{L A B}-x_{\max , L A B}\right)}\right)\left(1-10^{\left(x_{E c}-x_{\max , E c}\right)}\right)\left(1-10^{\left(x_{S a}-x_{\max , S a}\right)}\right)\right] I_{L E S} \\
t=0 \quad x_{E c}=x_{E c, 0} x_{S a}=x_{S a, 0} \quad x_{L A B}=x_{L A B, 0}
\end{gathered}
$$

where $I_{E S L}, I_{S E L}$, and $I_{L E S}$ are the competition coefficients representing the effects of $S$. aureus and LAB (Fresco) on E. coli, E. coli and LAB (Fresco) on S. aureus, and E. coli and S. aureus on LAB (Fresco), respectively.

The following secondary square root models were used to incorporate the temperature effect on the growth parameter in the above equations

$$
\begin{aligned}
& \mu_{\max }^{E c}=\left[b_{T, E c} \cdot\left(T-T_{\min , E c}\right)\right]^{2} ; \mu_{\max }^{S a}=\left[b_{T, S a} \cdot\left(T-T_{\min , S a}\right)\right]^{2} ; \mu_{\max }^{L A B}=\left[b_{T, L A B} \cdot\left(T-T_{\min , L A B}\right)\right]^{2} ; \\
& t_{\lambda}^{E c}=\frac{1}{\left[b_{\lambda, E c} \cdot\left(T-T_{\min , E c}\right)\right]^{2}} ; t_{\lambda}^{S a}=\frac{1}{\left[b_{\lambda, S a} \cdot\left(T-T_{\min , S a}\right)\right]^{2}} ; t_{\lambda}^{L A B}=\frac{1}{\left[b_{\lambda, L A B} \cdot\left(T-T_{\min , L A B}\right)\right]^{2}} .
\end{aligned}
$$

The tertiary H-GD model (Equation $(11 \mathrm{a}, \mathrm{b}, \mathrm{c})$ ) contains 15 parameters (Equation (12)).

$$
p_{H-G D}=\left\{\begin{array}{l}
I_{E S L} ; I_{S E L} ; I_{L E S} ; x_{\max , E c} ; x_{\max , S a} ; x_{\max , L A B} ; \\
b_{T, E c} ; b_{T, S a} ; b_{T, L A B} ; T_{\min , E c} ; T_{\min , S a} ; T_{\min , L A B} ; b_{\lambda, E c} ; b_{\lambda, S a} ; b_{\lambda, L A B}
\end{array}\right\}
$$

where $p_{H M-G D}$ is the vector of the evaluated parameters from the entire growth curves for the simultaneous competitive bacterial growth in milk at different temperatures and Fresco inoculum levels.

The tertiary H-GD model was tested for four cases $\left(\mathrm{H}-\mathrm{GD}_{1}, \mathrm{H}-\mathrm{GD}_{2}, \mathrm{H}-\mathrm{GD}_{3}\right.$, and $\left.\mathrm{H}-\mathrm{GD}_{4}\right)$. In H-GD 1 , only the interaction coefficients $\left(I_{E S L}, I_{S E L}\right.$, and $\left.I_{L E S}\right)$ were evaluated by applying one-step kinetic data analysis to predict the simultaneous growth of $S$. aureus, E. coli, and LAB in milk. The remaining parameters in Equation (12), optimized by nonlinear regression analysis for the tertiary $\mathrm{HM}_{1-\mathrm{S}}$ for single cultures, were fixed constant. Then, 
the first six parameters were evaluated $p_{H-G D}=\left\{I_{E S L} ; I_{S E L} ; I_{L E S} ; x_{\max , E c} ; x_{\max , S a} ; x_{\max , L A B}\right\}$ in $\mathrm{H}-\mathrm{GD}_{2}$. Next, in $\mathrm{H}-\mathrm{GD}_{3}$, all parameters (Equation (12)) of the tertiary H-GD model (Equation $(11 \mathrm{a}-\mathrm{c})$ ) were optimized. Finally, in $\mathrm{H}-\mathrm{GD}_{4}$, the interaction coefficients were excluded $\left(I_{\mathrm{ESL}}, I_{\mathrm{SEL}}\right.$, and $I_{\mathrm{LES}}$ equal one). The practical usefulness of this model is that all model parameters for the prediction of the competition between E. coli, S. aureus, and LAB in milk could be estimated from the individual growth of single species.

The suitability of the tertiary H-GD model to fit the whole set of observation points in the four cases was evaluated with goodness-of-fit indexes including the global sum of the square error $(S S E)$ and the root mean square error $(R M S E)$.

The prediction capability of the tertiary H-GD model for three cases with interaction coefficients $\left(\mathrm{H}-\mathrm{GD}_{1}, \mathrm{H}-\mathrm{GD}_{2}\right.$, and $\left.\mathrm{H}-\mathrm{GD}_{3}\right)$ was also tested through bias $\left(B_{f}\right)$ and accuracy $\left(A_{f}\right)$ factors [28] on the independent data sets not used in the one-step data analysis for the prediction of the simultaneous competitive growth of E. coli, S. aureus, and Fresco in milk at different temperatures $\left(10-37^{\circ} \mathrm{C}\right)$ and Fresco inoculum levels. The performance of the $\mathrm{H}-\mathrm{GD}_{1}$ model in the present study was also evaluated with the residual error (RE), which is the value of $x^{\exp }$ minus $x^{\mathrm{cal}}$ for each observation point of modeling with the independent validation data sets [31].

The commercial process-engineering software Athena Visual Workbench was used for parameter evaluation of the primary, secondary, and tertiary models; model prediction; and modeling the microbial interaction. Microsoft Excel (Microsoft, Redmond, WA, USA) was used for calculation of the statistical indices $S S E, R_{a d j}{ }^{2}, R M S E, R S S E$, and $C R_{\mathrm{T}}$, and the validation factors (bias $\left(B_{f}\right)$ and accuracy $\left(A_{f}\right)$ ).

\section{Results and Discussion}

The experimental counts of $S$. aureus, E. coli, and LAB Fresco in single cultivation as well as in co-culture were collected from the previously published data $[2,3,19]$ and used to develop the tertiary mathematical models.

\subsection{Comparison of One-and Two-Step Kinetic Data Analysis to Predict the Growth of Single Cultures in Milk}

\subsubsection{Two-Step Data Analysis and Evaluation of Model Performance}

The effect of temperature on the individual growth of $S$. aureus, E. coli, and LAB Fresco in milk at temperatures of $10-37^{\circ} \mathrm{C}$ was modeled in two steps. Firstly, to determine the pertinent kinetic parameters, such as $\mu_{\max }, t_{\lambda}, x_{0}$, and $x_{\max }$, the growth curves were fitted with the HM (Equation (1)) and expressed as the ordinary differential equation in its modified form. Then, the suitable secondary models were used to analyze the effect of temperature on $\mu_{\max }$ and $t_{\lambda}$. The classic method for the two-step method analysis allows the selection of good input values of parameters; thus, the regression analysis converts easily and quickly. Estimates of the primary HM and secondary square root models, summarized in Table 1, were integrated in the tertiary $\mathrm{HM}_{2-\mathrm{S}}$ and used for forward predictions.

One major drawback of this standard approach is the accumulation and propagation of errors in each step of data analysis during model development, which may affect the accuracy of the tertiary model [12]. The goodness-of-fit indices constructed through twostep data analysis (SSE, RMSE, and $R_{a d j}{ }^{2}$ ) are shown in Table 2.

The RMSE values obtained from the tertiary models constructed through two-step data analysis were $0.449,0.341$, and $0.280 \log$ CFU $\mathrm{mL}^{-1}$ for single cultures of $S$. aureus, E. coli, and Fresco in milk, respectively. Adjusted determination coefficients $\left(R_{a d j}{ }^{2}\right)$ were greater than 0.944 for all tertiary $\mathrm{HM}_{2-\mathrm{s}}$. For the evaluation of the RMSE values for microbial growth prediction in milk, Jia et al. [32] mentioned values in the range of 0.4 to $0.8 \log \mathrm{CFU} \mathrm{mL}^{-1}$ as being reasonably accurate. Our two-step approach using $\mathrm{HM}_{2-\mathrm{s}}$ for growth prediction of all the above populations easily meets this requirement. 
Table 1. Parameters of $\mathrm{HM}_{2-\mathrm{S}}$ with the $95 \%$ confidence limit determined by the two-step analysis method used for the growth prediction of single cultures of S. aureus (Sa), E. coli (Ec), and Fresco (LAB) in milk.

\begin{tabular}{|c|c|c|c|}
\hline Parameter & $\mathrm{HM}_{2-\mathrm{s}} \mathrm{Sa}$ & $\mathrm{HM}_{2-\mathrm{s}} \mathrm{Ec}$ & $\mathrm{HM}_{2-\mathrm{s}} \mathrm{LAB}$ \\
\hline$x_{0,10}{ }^{1}\left[\log\right.$ CFU mL $\left.{ }^{-1}\right]$ & $3.46 \pm 0.09$ & $2.99 \pm 0.01$ & $4.34 \pm 0.10$ \\
\hline$x_{0,12}\left[\log\right.$ CFU mL $\left.\mathrm{mL}^{-1}\right]$ & $2.44 \pm 0.18$ & $3.08 \pm 0.30$ & $4.21 \pm 0.20$ \\
\hline$x_{0,15}\left[\log\right.$ CFU mL $\left.\mathrm{mL}^{-1}\right]$ & $4.15 \pm 0.26$ & $2.14 \pm 0.39$ & $4.38 \pm 0.14$ \\
\hline$x_{0,18}\left[\log\right.$ CFU mL $\left.\mathrm{mL}^{-1}\right]$ & $3.27 \pm 0.12$ & $3.45 \pm 0.15$ & $4.38 \pm 0.10$ \\
\hline$x_{0,21}\left[\log\right.$ CFU mL $\left.\mathrm{mL}^{-1}\right]$ & $3.45 \pm 0.13$ & $3.09 \pm 0.19$ & $4.19 \pm 0.22$ \\
\hline$x_{0,25}\left[\log\right.$ CFU mL $\left.\mathrm{mL}^{-1}\right]$ & $3.22 \pm 0.12$ & $3.16 \pm 0.21$ & $5.42 \pm 0.17$ \\
\hline$x_{0,30}\left[\log \mathrm{CFU} \mathrm{mL} \mathrm{mL}^{-1}\right]$ & $3.33 \pm 0.12$ & $3.30 \pm 0.14$ & $4.24 \pm 0.09$ \\
\hline$x_{0,35}\left[\log\right.$ CFU mL $\left.L^{-1}\right]$ & $3.38 \pm 0.19$ & $3.35 \pm 0.12$ & $4.23 \pm 0.20$ \\
\hline$x_{0,37}\left[\log\right.$ CFU mL $\left.{ }^{-1}\right]$ & $2.75 \pm 0.29$ & $3.24 \pm 0.30$ & $4.40 \pm 0.13$ \\
\hline$x_{\max }^{2}\left[\log\right.$ CFU mL $\left.{ }^{-1}\right]$ & 8.12 & 8.36 & 9.19 \\
\hline$b_{\mathrm{T}}\left[{ }^{\circ} \mathrm{C}^{-1} \mathrm{~h}^{-0.5}\right]$ & $0.0441 \pm 0.0032$ & $0.0400 \pm 0.0033$ & $0.0362 \pm 0.0031$ \\
\hline$T_{\min }\left[{ }^{\circ} \mathrm{C}\right]$ & $5.67 \pm 1.23$ & $3.09 \pm 1.75$ & $-0.11 \pm 2.27$ \\
\hline$b_{\lambda}\left[{ }^{\circ} \mathrm{C}^{-1} \mathrm{~h}^{-0.5}\right]$ & $0.0297 \pm 0.0057$ & $0.0507 \pm 0.0134$ & $0.0369 \pm 0.0081$ \\
\hline
\end{tabular}

${ }^{1} x_{0}$ initial concentration of microorganisms $\left(x_{0}=\log N_{0}\right)$; the second numerical subscript is the temperature $2 x_{\max }$ is the average value of the maximum bacterial counts. The corresponding standard deviations for S. aureus,

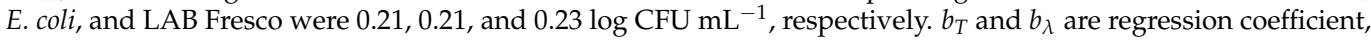
$T_{\min }$ is theoretical minimum temperature for growth.

Table 2. Goodness-of-fit indices of the tertiary $\mathrm{HM}_{2-\mathrm{S}}$ constructed through two-step data analysis for growth prediction of single cultures of S. aureus (Sa), E. coli (Ec), and Fresco (LAB) in milk.

\begin{tabular}{|c|c|c|c|}
\hline Parameter & $\mathrm{HM}_{2-\mathrm{s}} \mathrm{Sa}$ & $\mathrm{HM}_{2-\mathrm{s}} \mathrm{Ec}$ & $\mathrm{HM}_{2-\mathrm{s}} \mathrm{LAB}$ \\
\hline$S S E\left[\log C F U \mathrm{~mL}^{-1}\right]^{2}$ & 37.982 & 20.887 & 13.127 \\
\hline$R M S E\left[\log C F U \mathrm{~mL}^{-1}\right]$ & 0.449 & 0.341 & 0.280 \\
\hline$R_{a d j}^{2}$ & 0.944 & 0.969 & 0.977 \\
\hline
\end{tabular}

Number of data points: $n_{\mathrm{Sa}}=188 ; n_{\mathrm{Ec}}=180 ; n_{\mathrm{LAB}}=168$. SSE is global sum of square, $R M S E$ is root mean square error, and $R_{a d j}{ }^{2}$ is adjusted determination coefficient.

\subsubsection{One-Step Data Analysis and Evaluation of Model Performance}

Despite the acceptable two-step approach indices, Dolan and Mishra [13] and Jewell [11] stated that the one-step approach better fits the data than the two-step method, which produces directly interpretable regression diagnostics and standard errors. Therefore, one-step data analysis was applied for direct construction of the tertiary $\mathrm{HM}_{1-S}$; however, it requires advanced knowledge and skills in statistics and computer programming [12]. With the assistance of the user interface in commercial process-engineering software Athena Visual Workbench, it was possible to adjust the initial values and visually inspect the agreement between the test call model data and experimental observations. In our study, for all cases of the one-step method, we used not only the parameters previously estimated by the two-step approach, but also the ability of Athena Visual Workbench to fix some of the parameters as constants as well as to optimize those that were not determined in the previous nonlinear regression analysis. The inability to estimate the parameters more reliably may also be caused by an insufficient number of experimental data points associated with the specific value of the observed factor. Therefore, for successful nonlinear regression one-step kinetic data analysis, high-quality data are necessary, and the initial estimated values should be as close to the final values of parameters as possible. However, according to Huang [12], suitable software with a graphical-user-interface can make it easier to perform the regression analysis. Finally, the results may be used to improve the experimental design and data collection.

The estimated parameters of the tertiary $\mathrm{HM}_{1-\mathrm{S}}$ constructed through one-step data analysis for single cultures of the strains considered in this study are summarized in Table 3, and the statistical goodness-of-fit indices are presented in Table 4. 
Table 3. Parameters of $\mathrm{HM}_{1-\mathrm{S}}$ with a $95 \%$ confidence limit determined by the one-step analysis method used for the growth prediction of single cultures of S. aureus (Sa), E. coli (Ec), and Fresco (LAB) in milk.

\begin{tabular}{|c|c|c|c|}
\hline Parameter & $\mathrm{HM}_{2-\mathrm{s}} \mathrm{Sa}$ & $\mathrm{HM}_{2-\mathrm{s}} \mathrm{Ec}$ & $\mathrm{HM}_{2-\mathrm{s}} \mathrm{LAB}$ \\
\hline$x_{0,10}{ }^{1}\left[\log \mathrm{CFU} \mathrm{mL}^{-1}\right]$ & $3.74 \pm 0.05$ & $3.05 \pm 0.03$ & $4.33 \pm 0.02$ \\
\hline$x_{0,12}\left[\log \mathrm{CFU} \mathrm{mL}^{-1}\right]$ & $2.14 \pm 0.03$ & $3.27 \pm 0.03$ & $4.29 \pm 0.04$ \\
\hline$x_{0,15}\left[\log\right.$ CFU mL $\left.\mathrm{mL}^{-1}\right]$ & $3.90 \pm 0.05$ & $2.77 \pm 0.08$ & $4.35 \pm 0.03$ \\
\hline$x_{0,18}\left[\log\right.$ CFU mL $\left.\mathrm{m}^{-1}\right]$ & $3.26 \pm 0.02$ & $3.21 \pm 0.03$ & $4.30 \pm 0.03$ \\
\hline$x_{0,21}\left[\log\right.$ CFU mL $\left.\mathrm{m}^{-1}\right]$ & $3.51 \pm 0.03$ & $3.25 \pm 0.03$ & $4.58 \pm 0.04$ \\
\hline$x_{0,25}\left[\log\right.$ CFU mL $\left.\mathrm{m}^{-1}\right]$ & $3.15 \pm 0.03$ & $3.13 \pm 0.03$ & $5.62 \pm 0.04$ \\
\hline$x_{0,30}\left[\log\right.$ CFU mL $\left.\mathrm{m}^{-1}\right]$ & $2.72 \pm 0.05$ & $3.20 \pm 0.02$ & $3.91 \pm 0.04$ \\
\hline$x_{0,35}\left[\log\right.$ CFU mL $\left.\mathrm{mL}^{-1}\right]$ & $3.71 \pm 0.04$ & $3.35 \pm 0.04$ & $4.26 \pm 0.03$ \\
\hline$x_{0,37}\left[\log\right.$ CFU mL $\left.{ }^{-1}\right]$ & $3.01 \pm 0.08$ & $3.04 \pm 0.04$ & $4.32 \pm 0.07$ \\
\hline$x_{\max }{ }^{2}\left[\log \mathrm{CFU} \mathrm{mL}^{-1}\right]$ & $8.08 \pm 0.02$ & $8.39 \pm 0.02$ & $9.11 \pm 0.01$ \\
\hline$b_{\mathrm{T}}\left[{ }^{\circ} \mathrm{C}^{-1} \mathrm{~h}^{-0.5}\right]$ & $0.0409 \pm 0.0001$ & $0.0421 \pm 0.0002$ & $0.0384 \pm 0.0002$ \\
\hline$T_{\min }\left[{ }^{\circ} \mathrm{C}\right]$ & $5.02 \pm 0.01$ & $4.16 \pm 0.04$ & $1.11 \pm 0.07$ \\
\hline$b_{\lambda}\left[{ }^{\circ} \mathrm{C}^{-1} \mathrm{~h}^{-0.5}\right]$ & $0.0302 \pm 0.0002$ & $0.0493 \pm 0.0001$ & $0.0343 \pm 0.0009$ \\
\hline
\end{tabular}

${ }^{1} x_{0}$ initial concentration of microorganisms $\left(x_{0}=\log N_{0}\right)$; the second numerical subscript is the temperature.

${ }^{2} b_{\mathrm{T}}$ and $b_{\lambda}$ are regression coefficients, $T_{\min }$ is theoretical minimum temperature for growth.

Table 4. Goodness-of-fit indices for the growth prediction of single cultures of S. aureus (Sa), E. coli, (Ec) and Fresco (LAB) in milk by tertiary one-step $\mathrm{HM}_{1-\mathrm{S}}$.

\begin{tabular}{|c|c|c|c|}
\hline Parameter & $\mathrm{HM}_{2-\mathrm{s}} \mathrm{Sa}$ & $\mathrm{HM}_{2-\mathrm{s}} \mathrm{Ec}$ & $\mathrm{HM}_{2-\mathrm{s}} \mathrm{LAB}$ \\
\hline$S S E\left[\log \mathrm{CFU} \mathrm{mL} \mathrm{m}^{-1}\right]^{2}$ & 14.587 & 9.528 & 6.786 \\
\hline$R M S E\left[\log C F U \mathrm{~mL}^{-1}\right]$ & 0.279 & 0.230 & 0.201 \\
\hline$R_{a d j}^{2}$ & 0.979 & 0.986 & 0.988 \\
\hline
\end{tabular}

Number of data points: $n_{\mathrm{Sa}}=188 ; n_{\mathrm{Ec}}=180 ; n_{\mathrm{LAB}}=168$. SSE is global sum of square, $R M S E$ is root mean square error, and $R_{a d j}{ }^{2}$ is adjusted determination coefficient.

The statistical evaluation RMSE, as shown in Table 4, are one-third lower on average for the one-step approach for single bacterial populations compared to the two-step approach. Other indices also support the finding that the one-step approach based on primary $\mathrm{HM}$ is superior in the prediction of the growth of all three bacterial populations in this study compared to the two-step modeling approach. For example, statistical differences between the modeling of one- and two-step approaches $\left(\Delta S S E_{m}\right)$ for the tertiary HMs were evaluated by post hoc analysis using Tukey's test, with the results presented in Table 5. The means $S S E\left(S S E_{m}=S S E / n\right)$ were regarded as statistically significant at the 0.01 level of significance $(p$-value $<0.01)$. The $\triangle S S E$ means that differ by a value $\geq C R_{T}$ were considered as significantly different from each other at the chosen level of significance.

Table 5. Critical range of the SSE means and the differences between each pair of SSE means by comparing the one- and two-step approaches.

\begin{tabular}{cccc}
\hline Parameter & $\mathbf{H M}_{\mathbf{2 - 1}} \mathbf{S a}^{\mathbf{S a}}$ & $\mathbf{H M}_{\mathbf{2 - 1}}$ Ec & $\mathbf{H M}_{\mathbf{2 - 1}}$ LAB $^{\text {E }}$ \\
\hline$C R_{\mathrm{T}}$ & 0.0800 & 0.0458 & 0.0264 \\
$\Delta S S E_{m}$ & 0.1244 & 0.0631 & 0.0377 \\
\hline
\end{tabular}

$\overline{C R}_{\mathrm{T}}$ is the critical range for Tukey's test, $\Delta \mathrm{SSE}_{\mathrm{m}}$ is statistical difference between the modeling of one- and two-step approaches.

\subsubsection{Model Validation}

Based on post hoc analysis using Tukey's test, $\mathrm{HM}_{1-\mathrm{s}}$, was chosen for validation using independent data sets of different isolates of $S$. aureus and E. coli obtained at different time periods and grown similarly in milk at a temperature range of $15-35{ }^{\circ} \mathrm{C}\left(n_{\mathrm{Sa}}=164\right)$ and $10-37^{\circ} \mathrm{C}\left(n_{E c}=134\right)$. The calculated values of $B_{f}$ and $A_{f}$ through the above-mentioned data sets are summarized in Table 6 . 
Table 6. Bias and accuracy of independent data sets of S. aureus (Sa), E. coli (Ec) during their growth as single cultures in milk.

\begin{tabular}{|c|c|c|}
\hline Factor & $\mathrm{HM}_{1-\mathrm{s}} \mathrm{Sa}$ & $\mathrm{HM}_{1-\mathrm{s}} \mathrm{Ec}$ \\
\hline$B_{f}$ & 1.076 & 0.911 \\
\hline$A_{f}$ & 1.170 & 1.200 \\
\hline
\end{tabular}

$A_{f}$ is the accuracy factor, $B_{f}$ is the bias factor.

A validation factor $B_{f}$ equal to one indicates that observations are equally distributed above and below predictions, producing a perfect agreement. In our validation study, the $B_{f}$ for $S$. aureus indicated a slight overestimation $\left(B_{f}>1\right.$; fail-safe model), whereas for E. coli, some underestimation was observed $\left(B_{f}<1\right.$; fail-dangerous model) of independent experimental data sets. The accuracy factors for both bacteria grown in milk indicate that, on average, predictions are approximately 1.2 factors of difference with respect to the observations. Validation indices $B_{f}$ and $A_{f}$ close to one generally confirm the acceptable growth prediction of microorganisms and an acceptable bias factor value for a predictive model is $0.75-1.25$ [33]. From this, it follows that the $\mathrm{HM}_{1-\mathrm{s}}$ one-step approach tertiary model exhibits considerable potential as a useful and efficient tool to improve growth predictions of the single cultures under study and can be employed as a more accurate and robust alternative method to the traditionally used two-step kinetic data analysis.

\subsection{Application of One-Step Kinetic Data Analysis to Predict the Growth of Co-Cultures in Milk}

Another challenge to determine the suitability of the one-step modeling approach was the application to the simultaneous prediction of competitive bacteria growth in milk at different temperatures and LAB Fresco inoculum levels. The H-GD model (Equation (11a-c)) with incorporated interaction coefficients values and secondary square models for $\mu$ and $t_{\lambda}$ was chosen in this work. The model was tested for four cases, as described above. In $\mathrm{H}-\mathrm{GD}_{1}$, only the interaction coefficients $\left(I_{E S L}, I_{S E L}\right.$, and $\left.I_{L E S}\right)$ were evaluated. The remaining parameters were replaced with those optimized by the one-step kinetic data analyses for single cultures (Equation (12)) and fixed. Similarly, in $\mathrm{H}_{-} \mathrm{GD}_{2}$, only the first six parameters $\left(I_{E S L} ; I_{S E L} ; I_{L E S} ; x_{\max , E c} ; x_{\max , S a} ; x_{\max , L A B}\right)$ were evaluated; finally, all parameters in Equation $\left(11 \mathrm{a}-\mathrm{c}\right.$ ) were optimized in $\mathrm{H}-\mathrm{GD}_{3}$. The last case, $\mathrm{H}-\mathrm{GD}_{4}$ did not consider any interactions among populations, as the coefficients $I_{E S L}, I_{S E L}$, and $I_{L E S}$ were fixed to 1 . The practical usefulness of this option is that all parameters for prediction of the E. coli, $S$. aureus, and LAB in co-cultures in milk could be estimated from the individual growth of a single species.

The results of the one-step model parameter estimations in the four cases of the H-GD model and their goodness-of-fit indices are summarized in Tables 7 and 8, respectively.

Based on the goodness-of-fit indices of the tertiary H-GD models provided in Table 8, it logically follows that the lowest values of the global SSE and RMSE were found for the $\mathrm{H}_{-} \mathrm{GD}_{3}$ model case, for which all parameters used (Equation (12)) were optimized. The global SSE and RMSE of the H-GD models that included the interaction coefficients ( $\mathrm{H}-\mathrm{GD}_{1}, \mathrm{H}-\mathrm{GD}_{2}$, and $\mathrm{H}-\mathrm{GD}_{3}$ ), even $\mathrm{H}-\mathrm{GD}_{1}$, in which only three interaction coefficients were optimized as model parameters, were obviously lower than those of $\mathrm{H}-\mathrm{GD}_{4}$, which indicated significantly improved accuracy between the observed and calculated values, as well as improved prediction performance [3].

However, it is disputable whether it is necessary to evaluate all parameters of the H-GD models with interaction coefficients using one-step analysis, as indicated by the negligible differences between the RMSE values and between the errors of the parameters estimated. It is clear that the fewer the parameters optimized, the lower the error values of the parameters. As such, the $\mathrm{H}-\mathrm{GD}_{1}$ model with only three parameters optimized appears to be a good option for growth prediction. 
Table 7. Parameters of the H-GD models with $95 \%$ confidence limits determined by the one-step analysis method used for co-culture growth prediction of S. aureus (Sa), E. coli (Ec), and Fresco (LAB) in milk.

\begin{tabular}{ccccc}
\hline Parameter & H-GD & H-GD & H-GD & H-GD $_{\mathbf{4}}$ \\
\hline$I_{E S L}$ & $0.760 \pm 0.007$ & $0.761 \pm 0.007$ & $0.818 \pm 0.014$ & 1 \\
$I_{S E L}$ & $1.061 \pm 0.007$ & $1.060 \pm 0.016$ & $0.973 \pm 0.020$ & 1 \\
$I_{L E S}$ & $0.906 \pm 0.004$ & $0.921 \pm 0.019$ & $0.934 \pm 0.033$ & 1 \\
$x_{\max , E c}\left[\log \mathrm{CFU} \mathrm{mL} \mathrm{C}^{-1}\right]$ & $* 8.36$ & $7.25 \pm 0.57$ & $7.23 \pm 0.78$ & $* 8.36$ \\
$x_{\max , S a}\left[\log \mathrm{CFU} \mathrm{mL} \mathrm{C}^{-1}\right]$ & $* 8.12$ & $7.21 \pm 0.72$ & $7.24 \pm 1.34$ & $* 8.12$ \\
$x_{\max , L A B}\left[\log \mathrm{CFU} \mathrm{mL} \mathrm{m}^{-1}\right]$ & $* 9.19$ & $8.93 \pm 0.07$ & $8.90 \pm 0.06$ & $* 9.19$ \\
$b_{T, E c}\left[{ }^{\circ} \mathrm{C}^{-1} \mathrm{~h}^{-0.5}\right]$ & $* 0.0421$ & $* 0.0421$ & $0.0410 \pm 0.0007$ & $* 0.0421$ \\
$b_{T, S a}\left[{ }^{\circ} \mathrm{C}^{-1} \mathrm{~h}^{-0.5}\right]$ & $* 0.0409$ & $* 0.0409$ & $0.0411 \pm 0.0004$ & $* 0.0409$ \\
$b_{T, L A B}\left[{ }^{\circ} \mathrm{C}^{-1} \mathrm{~h}^{-0.5}\right]$ & $* 0.0384$ & $* 0.0384$ & $0.0391 \pm 0.0007$ & $* 0.0384$ \\
$T_{\min , E c}\left[{ }^{\circ} \mathrm{C}\right]$ & $* 4.16$ & $* 4.16$ & $4.18 \pm 8.9 \times 10^{-4}$ & $* 4.16$ \\
$T_{\min , S a}\left[{ }^{\circ} \mathrm{C}\right]$ & $* 5.02$ & $* 5.02$ & $5.04 \pm 9.0 \times 10^{-3}$ & $* 5.02$ \\
$T_{\min , L A B}\left[{ }^{\circ} \mathrm{C}\right]$ & $* 1.11$ & $* 1.11$ & $0.48 \pm 3.0 \times 10^{-5}$ & $* 1.11$ \\
$b_{\lambda, E c}\left[{ }^{\circ} \mathrm{C}^{-1} \mathrm{~h}^{-0.5}\right]$ & $* 0.0493$ & $* 0.0493$ & $0.0493 \pm 1.1 \times 10^{-5}$ & $* 0.0493$ \\
$b_{\lambda, S a}\left[{ }^{\circ} \mathrm{C}^{-1} \mathrm{~h}^{-0.5}\right]$ & $* 0.0302$ & $* 0.0302$ & $0.0303 \pm 2.1 \times 10^{-5}$ & $* 0.0302$ \\
$b_{\lambda, L A B}\left[{ }^{\circ} \mathrm{C}^{-1} \mathrm{~h}^{-0.5}\right]$ & $* 0.0343$ & $* 0.0343$ & $0.0343 \pm 3.5 \times 10^{-5}$ & $* 0.0343$ \\
\hline
\end{tabular}

* Parameters optimized by the one-step kinetic data analyses for single cultures. $x_{\max }$ is the average value of the maximum bacterial counts for S. aureus (Sa), E. coli (Ec), and Fresco (LAB), respectively. $b_{\mathrm{T}}$ and $b_{\lambda}$ are regression coefficient, $T_{\min }$ is theoretical minimum temperature for growth.

Table 8. Goodness of fit indexes of the H-GD model cases for growth of a co-culture of S. aureus, E. coli, and Fresco in milk.

\begin{tabular}{ccccc}
\hline Index & H-GD $_{\mathbf{1}}$ & H-GD $_{\mathbf{2}}$ & H-GD $_{\mathbf{3}}$ & H-GD $_{\mathbf{4}}$ \\
\hline SSE $\left[\log \mathrm{CFU} \mathrm{mL} \mathrm{mL}^{-1}\right]^{2}$ & 176.07 & 162.95 & 156.82 & 427.93 \\
RMSE $[\log \mathrm{CFU} \mathrm{mL}$ & 0.370 & 0.370 & 0.608 \\
\hline
\end{tabular}

Number of all data points for co-culture growth S. aureus, E. coli and Fresco $n=1158$. SSE is global sum of square, RMSE is root mean square error.

The prediction ability of the cases of the tertiary H-GD model were tested using the independent data sets of the simultaneous competitive bacteria growth in milk at different temperatures and Fresco inoculum levels that were not used in the one-step modeling. The values of $B_{f}$ and $A_{f}$ calculated on the above-mentioned independent data sets $(n=136$ for each microorganism) are summarized in Table 9.

Table 9. Bias and accuracy on the independent data sets of co-culture growth of E. coli (Ec), S. aureus (Sa), and Fresco (LAB) culture in milk.

\begin{tabular}{cccc}
\hline Index & H-GD $_{\mathbf{1}}$ & H-GD $_{\mathbf{2}}$ & H-GD $_{\mathbf{3}}$ \\
\hline$B_{f}{ }^{E c}$ & 1.001 & 0.990 & 0.989 \\
$A_{f}^{E c}$ & 1.070 & 1.074 & 1.079 \\
$B_{f} S a$ & 0.996 & 0.987 & 0.986 \\
$A_{f} S a$ & 1.073 & 1.069 & 1.068 \\
$B_{f}{ }^{L A B}$ & 1.011 & 0.998 & 1,000 \\
$A_{f}{ }^{L A B}$ & 1.035 & 1.036 & 1.039 \\
\hline
\end{tabular}

$A_{f}$ is the accuracy factor, $B_{f}$ is the bias factor.

It is difficult to judge which of the H-GD competition models provides the most accurate prediction for describing the co-culture growth of E. coli, S. aureus, and Fresco culture in milk from the results shown in Table 9. All the factors are very close to 1.0 and all tested model cases have comparable predictive ability. However, the validation factors also confirm the advantage of the $\mathrm{H}-\mathrm{GD}_{1}$ case, in which only the interaction coefficients were evaluated, and the other parameters (Equation (12)) from one-step kinetic data analysis of 
single cultures were fixed. Referring to the validation data sets, the RMSE of the predictions of the $\mathrm{H}-\mathrm{GD}_{1}, \mathrm{H}-\mathrm{GD}_{2}$, and $\mathrm{H}-\mathrm{GD}_{3}$ options of the one-step approach were $0.325,0.333$, and 0.345 , respectively. They are close to the RMSE of the nonlinear regression in Table 8 , which is why the overall predictions may be considered as reasonably accurate.

Based on the results obtained for the pure cultures and simultaneous competitive bacteria growth in milk at different temperatures and Fresco inoculum levels, we recommend the following procedure to predict their competitive growth: Apply one-step analysis to construct directly the tertiary model to determine the parameters for the prediction of the growth of single cultures and then, from the practical point of view, only evaluate the interaction coefficients to describe interspecies competition growth.

The $\mathrm{H}_{-} \mathrm{GD}_{1}$ one-step approach model was chosen to visually demonstrate the prediction of the simultaneous growth of E. coli, S. aureus, and a starter culture of LAB Fresco. As shown in Figure 1, the predicted co-culture growth curves using the $\mathrm{H}-\mathrm{GD}_{1}$ model are sufficiently in agreement with the observed growth curves data in milk. Optimizing the interaction coefficients provided good performance under all tested conditions. From the application of this model, we found that the presence of LAB clearly induced the early stationary phase of E. coli, S. aureus; the larger the initial population of LAB Fresco, the greater the suppression of E. coli and S. aureus in the co-culture [3]. For example, the maximum densities reached by E. coli and S. aureus at 12 and $30^{\circ} \mathrm{C}$ were kept under 5.1 and $3.8 \log \mathrm{CFU} \mathrm{mL} \mathrm{m}^{-1}$ and 5.1 and $5.2 \log \mathrm{CFU} \mathrm{mL}{ }^{-1}$, respectively, in co-cultures with Fresco inoculum at $10^{6} \mathrm{CFU} \mathrm{mL}{ }^{-1}$. Thus, inocula of Fresco higher than $5 \log \mathrm{CFU} \mathrm{mL} \mathrm{m}^{-1}$ managed to control the outgrowths by E. coli and S. aureus.
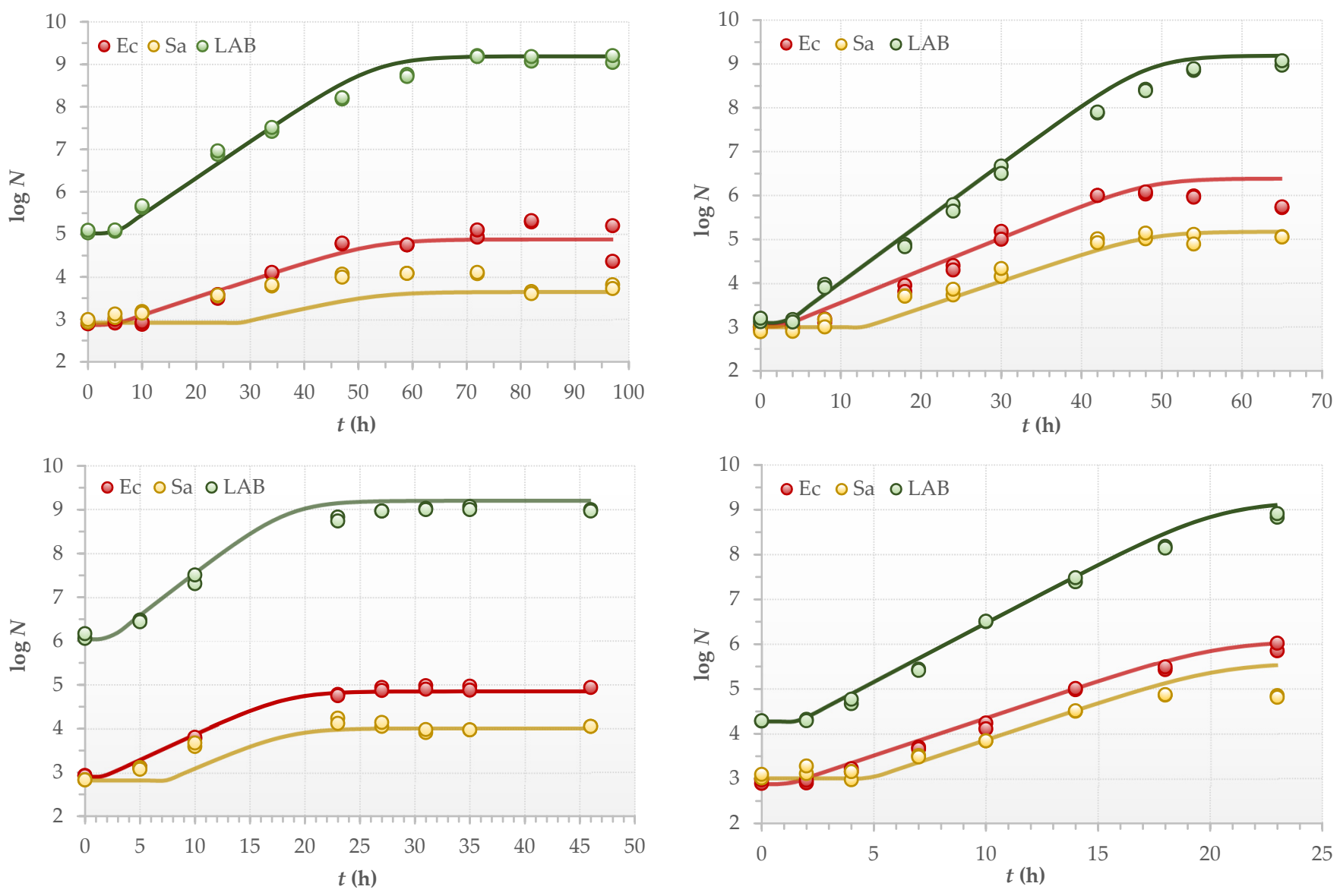

Figure 1. Co-culture growth of E. coli, S. aureus, and four different inocula of LAB Fresco in milk at $12{ }^{\circ} \mathrm{C}$ (upper left, $N_{0, L A B} \sim 5 \log \mathrm{CFU} \mathrm{mL}{ }^{-1}$ ), $15^{\circ} \mathrm{C}$ (upper right, $N_{0, L A B} \sim 3 \log \mathrm{CFU} \mathrm{mL}{ }^{-1}$ ), $18^{\circ} \mathrm{C}\left(\right.$ lower left, $N_{0, L A B} \sim 6 \log \mathrm{CFU} \mathrm{mL}^{-1}$ ), and $21{ }^{\circ} \mathrm{C}$ (lower right, $N_{0, L A B} \sim 4 \log \mathrm{CFU} \mathrm{mL}{ }^{-1}$ ). The continuous lines represent the growth predicted by the H-GD1-model and dots represent the actual logarithmic counts $(\log N)$ in selected time intervals. 
The analysis of the residuals between the observed and predicted values in co-culture growth also showed that $83.1 \%$ of the E. coli data (113/136), 96.3\% of the LAB Fresco data $(131 / 136)$ and $88.2 \%$ of the $S$. aureus data $(120 / 136)$ were in the range of the narrow acceptable values, namely, between +0.5 and $-0.5 \log$ CFU mL ${ }^{-1}$ [31]. The above evaluation of the $\mathrm{HGD}_{1}$ model with one-step kinetic data analysis for co-culture growth shows promise for isothermal prediction but for applications under dynamic conditions.

\section{Conclusions}

Four options of a co-culture growth model combining the primary Huang and Giménez and Dalgaard models were introduced and evaluated within a one-step approach methodology. The statistical indices showed acceptable results regarding the prediction capability of the co-culture models, even when the lowest number of parameters $(n=3)$ was optimized, and the others were adopted from one-step analysis of the participating single cultures. Despite the complexity of one-step modeling of bacterial growth in cocultures, the outputs may be considered in various types of lactic acid fermentation or in artisanal cheese-making technology. The models concerned with the individual growth of bacteria can be used in growth prediction in early stages; the one-step approach involving co-culture growth interactions can be applied for later phases of the fermentation processes. The presented approach can be also considered as one of the options for how to incorporate microbial interactions in exposure assessment.

Author Contributions: Conceptualization, P.A. and L'.V.; methodology, P.A. and A.M.; validation, P.A. and L'.V.; formal analysis, P.A., L'.V. and A.M.; investigation, A.M.; resources, A.M. and L'.V.; writing-original draft preparation, P.A. and L'.V.; writing-review and editing, P.A., L'.V. and A.M.; visualization, P.A. and L'.V.; supervision, L'.V.; project administration, P.A. and L'.V.; funding acquisition, P.A. and L'.V. All authors have read and agreed to the published version of the manuscript.

Funding: This research was funded by the Slovak Research and Development Agency, grant number APVV-19-0031 and the Scientific Grant Agency of the Ministry of Education, Science, Research and Sports of the Slovak Republic and Slovak Academy of Sciences, grant numbers KEGA 035STU-4/2021 and VEGA 1/0532/18.

Institutional Review Board Statement: Not applicable.

Informed Consent Statement: Not applicable.

Data Availability Statement: The data presented in this study are available upon reasonable request from the corresponding author.

Conflicts of Interest: The authors declare no conflict of interest.

\section{References}

1. Le Marc, Y.; Valík, L'; Medved'ová, A. Modelling the effect of the starter culture on the growth of Staphylococcus aureus in milk. Intern. J. Food Microbiol. 2009, 129, 306-311. [CrossRef] [PubMed]

2. Valík, L'.; Ačai, P. Application of competitive models in predicting the simultaneous growth of Staphylococcus aureus and lactic acid bacteria in milk. Food Control 2018, 87, 145-152. [CrossRef]

3. Ačai, P.; Medved'ová, A.; Mančušková, T.; Valík, L'. Growth prediction of two bacterial populations in co-culture with lactic acid bacteria. Food Sci. Technol. Int. 2019, 25, 692-700. [CrossRef]

4. Medved'ová, A.; Valík, L'.; Liptáková, D. Study of the Fresco culture inhibitory effect against Staphylococcus aureus in milk and in lump cheeses. J. Food Nutr. Res. 2011, 50, 193-198.

5. Medved'ová, A.; Koňuchová, M.; Kvočiková, K.; Hatalová, I.; Valík, L'. Effect of Lactic Acid Bacteria Addition on the Microbiological Safety of Pasta-Filata Types of Cheeses. Front. Microbiol. 2020, 11, 612528. [CrossRef]

6. Lehotová, V.; Antálková, V.; Medved'ová, A.; Valík, L'. Quantitative Microbiological Analysis of Artisanal Stretched Cheese Manufacture. Appl. Sci. 2021, 11, 2680. [CrossRef]

7. Medved'ová, A.; Šipošová, P.; Mančušková, T.; Valík, L'. The effect of salt and temperature on the growth of Fresco culture. Fermentation 2019, 5, 3390. [CrossRef]

8. Summary Reports of Zoonoses, Food-Borne and Water-Borne Diseases in the Slovak Republic (2016-2019); Ministry of Agriculture and Rural Development: Bratislava, Slovakia, 2020. Available online: https: / www.mpsr.sk/?navID=47\&sID=111\&navID2=506 (accessed on 30 July 2021). 
9. Whilshaw, G.A.; Cheasty, T.; Smith, H.R. Escherichia coli. In Microbiological Safety and Quality of Food, 1st ed.; Lund, B.M., Baird-Parker, T.C., Gould, G.W., Eds.; Aspen Publishers: Gaithersburg, MA, USA, 2000; Volume 1, pp. 1136-1178.

10. Whiting, R.; Buchanan, R. A classification of models for predictive microbiology. Food Microbiol. 1993, 10, $175-177$.

11. Jewell, K. Comparison of 1-step and 2-step methods of fitting microbiological models. Intern. J. Food Microbiol. 2012, 160, $145-161$. [CrossRef] [PubMed]

12. Huang, L. IPMP Global Fit—A one-step direct data analysis tool for predictive. Intern. J. Food Microbiol. 2017, 262, 38-48. [CrossRef]

13. Dolan, K.D.; Mishra, D.K. Parameter estimation in food science. Annu. Rev. Food Sci. Technol. 2013, 4, 401-422. [CrossRef]

14. Den Besten, H.B.B. Two complementary approaches to quantify variability in heat resistance of spores of Bacillus subtilis. Int. J. Food Microbiol. 2017, 253, 48-53. [CrossRef] [PubMed]

15. Li, M.; Huang, L.; Zhu, Y.; Wei, Q. Growth of Clostridium perfringens in roasted chicken and braised beef during cooling-One-step dynamic analysis and modeling. Food Control 2020, 106, 106739. [CrossRef]

16. Jia, Z.; Peng, Y.; Yan, X.; Zhang, Z.; Fang, T.; Li, C. One-step kinetic analysis of competitive growth of Salmonella spp. and background flora in ground chicken. Food Control 2020, 117, 107103. [CrossRef]

17. Tarlak, F. Development and validation of one-step modelling approach for prediction of mushroom spoilage. J. Food Nutr. Res. 2020, 59, 281-289.

18. Tarlak, F.; Khosravi-Darani, K. Development and validation of growth models using one-step modelling approach for determination of chicken meat shelf-life under isothermal and non-isothermal storage conditions. J. Food Nutr. Res. 2021, 60, 76-86.

19. Ačai, P.; Valík, L'; Medved'ová, A.; Rosskopf, F. Modelling and predicting the simultaneous growth of Escherichia coli and lactic acid bacteria in milk. Food Sci. Technol. Int. 2016, 22, 475-484. [CrossRef]

20. ISO 6888-1. Microbiology of Food and Animal Feeding Stuffs. Horizontal Method for the Enumeration of Coagulase-Positive Staphylococci (Staphylococcus aureus and Other Species). Part 1: Technique Using Baird-Parker Agar Medium; International Organization of Standardization (ISO): Geneva, Switzerland, 2001; pp. 1-22.

21. National Standard Method F23. Enumeration of Enterobacteriaceae by the Colony Count Technique, Evaluations and Standards Laboratory; Public Health Authority: Bratislava, Slovakia, 2005; pp. 1-23.

22. ISO 15214. Microbiology of Food and Animal Feeding Stuffs. Horizontal Method for the Enumeration of Mesophilic Lactic Acid Bacteria. Colony-Count Technique at $30^{\circ} \mathrm{C}$; International Organization of Standardization (ISO): Geneva, Switzerland, 2002 ; pp. 1-12.

23. Havlicek, L.L.; Crain, R.D. Practical Statistics for the Physical Sciences; ACS Professional Reference Book; American Chemical Society: Washington, DC, USA, 1988; pp. 236-328.

24. Huang, L. Optimization of a new mathematical model for bacterial growth. Food Control 2013, 32, 283-288. [CrossRef]

25. Giménez, B.; Dalgaard, P. Modelling and predicting the simultaneous growth of Listeria monocytogenes and spoilage microorganisms in cold-smoked salmon. J. Appl. Microbiol. 2004, 96, 96-109. [CrossRef]

26. Ratkowsky, D.A.; Olley, J.; McMeekin, T.A.; Ball, A. Relationship between temperature and growth rate of bacterial cultures. J. Bacteriol. 1982, 149, 1-5. [CrossRef]

27. Huang, L. Mathematical modeling and validation of growth of Salmonella Enteritidis and background microorganisms in potato salad-One-step kinetic analysis and model development. Food Control 2016, 68, 69-76. [CrossRef]

28. Baranyi, J.; Pin, C.; Ross, T. Validating and comparing predictive models. Intern. J. Food Microbiol. 1999, 48, 159-166. [CrossRef]

29. Medved'ová, A.; Valík, L'.; Sirotná, Z.; Liptáková, D. Growth characterization of Staphylococcus aureus in milk: A quantitative approach. Czech J. Food Sci. 2009, 27, 443-453. [CrossRef]

30. Liptáková, D.; Valík, L'; Medved'ová, A.; Hudecová, A. Quantitative analysis of growth of Escherichia coli in co-culture with Lactococcus lactis subsp. lactis in milk. Slovak J. Anim. Sci. 2008, 41, 91-97.

31. Oskar, T. General regression neural network and Monte Carlo simulation model for survival and growth of Salmonella on raw chicken skin as a function of serotype, temperature and time for use in risk assessment. J. Food Prot. 2009, 72, 2078-2087. [CrossRef]

32. Jia, Z.; Huang, L.; Wei, Z.; Yao, Y.; Fang, T.; Li, C. Dynamic kinetic analysis of growth of Listeria monocytogenes in pasteurized cow milk. J. Dairy Sci. 2021, 104, 2654-2667. [CrossRef]

33. Pérez-Rodríguez, F.; Valero, A. Predictive Microbiology in Foods, 1st ed.; Springer: Heidelberg, Germany, 2013 ; pp. 51-55. 